\title{
Maternal, neonatal and child health in Pakistan: towards the MDGs by moving from desire to reality
}

\author{
A.F. Shadoul, ${ }^{1}$ F. Akhtar ${ }^{2}$ and K.M. Bile
}

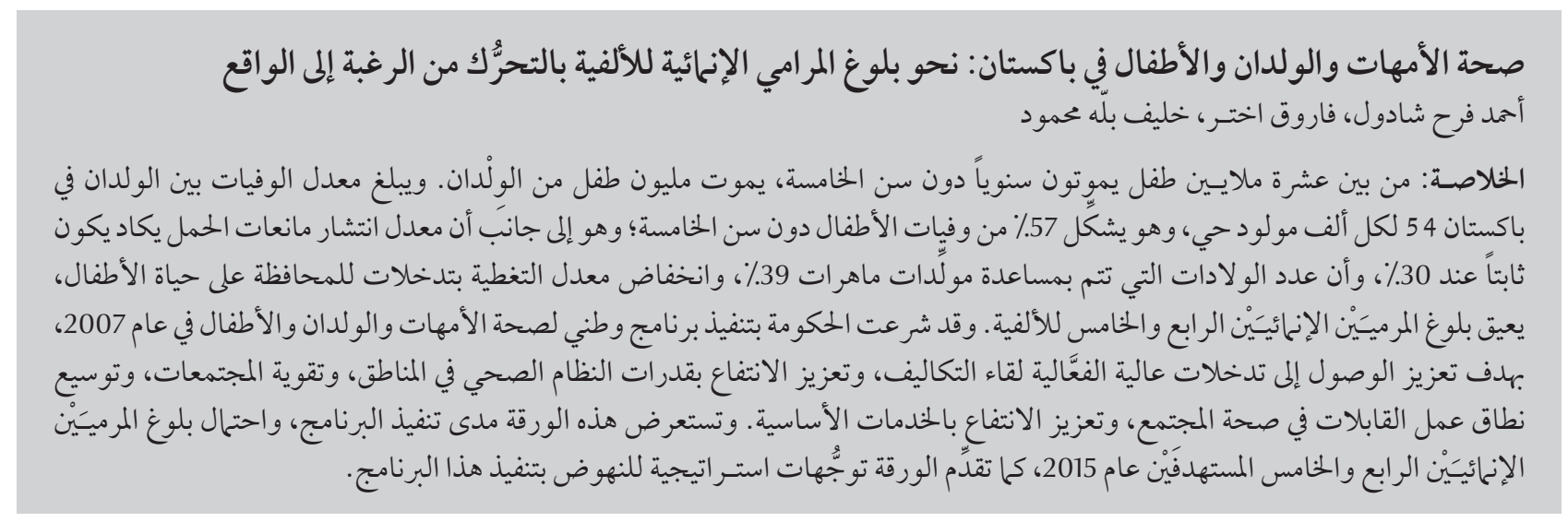

ABSTRACT Of the 10 million annual deaths of children below five years of age, four million are neonates. Pakistan's neonatal mortality rate of 54/1000 live births, which accounts for $57 \%$ of the under-five mortality, the contraceptive prevalence rate stagnating at $30 \%$, the meagre number of deliveries assisted by skilled birth attendants (39\%) and the low coverage of cost-effective child survival interventions hamper the achievement of Millennium Development Goals (MDGs) 4 and 5. The Government launched the national maternal, neonatal and child health programme in 2007 to promote access to evidence-based cost-effective interventions; strengthen district health system capacities; empower communities; expand the community midwives' cadre; and promote utilization of essential services. This paper reviews the implementation of the programme and the likelihood of attaining the MDG4 and 5 targets by 2015, and provides strategic directions for scaling-up programme implementation.

Santé de la mère, du nouveau-né et de l'enfant au Pakistan: atteindre les objectifs du Millénaire pour le développement en passant du rêve à la réalité

RÉSUMÉ Parmi les dix millions de décès d'enfants de moins de cinq ans, quatre millions concernent des nouveau-nés. Avec un taux de mortalité néonatale de 54 pour 1000 naissances vivantes (ce qui représente $57 \%$ de la mortalité des moins de cinq ans), un pourcentage de prévalence de la contraception qui stagne à $30 \%$, un nombre très faible d'accouchements assistés par des professionnelles qualifiées (39\%) et une couverture insuffisante en interventions rentables de survie infantile, il est difficile d'atteindre les objectifs 4 et 5 du Millénaire pour le développement au Pakistan. En 2007, le gouvernement a lancé le programme pour la santé de la mère, du nouveau-né et de l'enfant, afin de favoriser l'accès à des interventions d'un bon rapport coût-efficacité et fondées sur des données factuelles, de renforcer les capacités des systèmes de santé de district, d'autonomiser les communautés, de former davantage de sages-femmes communautaires qualifiées et d'encourager le recours aux services essentiels. Cet article étudie la mise en œuvre du programme et la probabilité de réaliser les objectifs 4 et 5 du Millénaire pour le développement d'ici à 2015. Il propose aussi des orientations stratégiques en vue de l'extension de la mise en œuvre du programme. 


\section{Introduction}

More than 10 million children younger than five years die globally every year $[1,2]$. About $41 \%$ of child deaths occur in sub-Saharan Africa and 34\% in south Asia [3]. Half of the worldwide deaths in children under five years occur in six countries alone, which include Pakistan, and $90 \%$ occur in 42 countries [4]. These deaths are attributed largely to diarrhoea (22\%), pneumonia (21\%), malaria (9\%), AIDS (3\%), measles (1\%) and neonatal causes (33\%), while being underweight confers an additional risk of mortality from infectious diseases [5]. Almost 4 million newborns suffer from moderate to severe birth asphyxia, with at least 800000 dying and a higher number developing sequelae every year [6].

World Health Organization (WHO) and United Nations Children's Fund (UNICEF) have estimated that one in every 38 women dies from pregnancy-related causes [7]. Recent estimates showed that 342900 maternal deaths occurred worldwide in 2008, down from 526300 in 1980, showing a $1.5 \%$ yearly rate of decline [8].

One-tenth of global maternal deaths (around 53000 ) occur annually in WHO's Eastern Mediterranean Region. Pakistan is responsible for almost $20 \%$ (11 000) of the regional maternal mortality, while more than $95 \%$ of this burden is shared by seven countries, namely Afghanistan, Iraq, Morocco, Pakistan, Somalia, Sudan and Yemen, which also suffer from high neonatal mortality rates (NNMRs) [9]. Ten countries harbour $67 \%$ of the burden of neonatal deaths, with Pakistan being the fourth country on the list, accounting for $7 \%$ of the global neonatal deaths [10].

The maternal mortality ratio (MMR) of 276/100 000 live births, under-five mortality rate (U5MR), infant mortality rate (IMR) and NNMR of $94 / 1000,78 / 1000$ and 54/1000 live births, respectively, are unacceptably high [11]. The contraceptive prevalence rate of $30 \%$, the unmet need for contraceptive services of $25 \%$ and total fertility rate of 4.1 would constrain the attainment of MillenniumDevelopment Goal (MDG) 5. The Pakistan demographic and health survey (PDHS) 2006-2007 indicates that $39 \%$ of births were assisted by skilled birth attendants , 34\% were facility based and $66 \%$ were home based, while $68 \%$ occurred in peripheral rural settings. Approximately $7.3 \%$ of births were delivered by caesarean section with wide disparities between urban and rural areas [12].

The IMR of $78 / 1000$ live births is higher than the averages of low-income countries and south Asia by $10 \%$ and $16 \%$, respectively [13]. High levels of child and maternal mortality and morbidity in Pakistan result from the interplay of a variety of factors, including the low status of women in society, poor nutrition, poor access to health services, particularly emergency obstetric and neonatal care (EmONC), rural-urban disparity, and poverty and illiteracy [14-16]. One-fifth of newborns are low birth weight, and $38 \%$ of under-five children are underweight, while anaemia remains highly prevalent among women (40\%) and under-five children (62\%) $[15,17]$. Over the past four decades, there has been a slow reduction in infant mortality, while neonatal mortality has remained virtually static at 54/1000 live births (PDHS 2006-2007) with most deaths occurring during the early neonatal period or first week of life. Moreover, high levels of perinatal mortality (159/1000 pregnancies) are associated with events occurring during late gestation, delivery, postpartum and the first week of life [11].

Health care provision in Pakistan involves the private and public sectors. The public sector is comprised of a large network exceeding 10000 health facilities, in addition to around 3000 family welfare centres run by the Ministry of Population Welfare with limited functional integration $[18,19]$. Pakistan also has a flourishing network of private health care providers with a larger utilization base. Most people initially seek curative care from the private sector; for instance $49 \%$ of diarrhoea cases initially seek care from private practitioners, and about $70 \%$ of private sector services are urban based [17]. Several nongovernmental organizations possessing varying capacities focus on provision of family planning (FP) services, mainly in urban areas. Traditional birth attendants and relatives are the major providers of delivery care in rural areas [11].

The health system's ability to respond and provide adequate and comprehensive quality services continues to remain limited, as is access to and utilization of preventive and curative health services. Availability of lady health workers and lady health visitors has increased substantially; however, the availability of women medical officers and community midwives (CMWs) remains very low. Similarly, basic and comprehensive EmONC is provided at various levels of the health system, though the coverage, access and utilization levels are unsatisfactory.

This paper aims to review the progress attained on maternal neonatal and child health $(\mathrm{MNCH})$ and evaluate the likelihood of Pakistan achieving its MDG 4 and 5 targets by 2015 .

\section{Methods}

More than 25 published documents and national surveys relating to $\mathrm{MNCH}$ in Pakistan were thoroughly reviewed, the major ones being PDHS 2006-2007; MNCH PC-1, National Health Policy 2001 and the draft policy 2010; Pakistan MDG reports and Pakistan Social and Living Standards Measurement Survey 2005-2006. Documents addressing $\mathrm{MNCH}$ policies, strategies and related estimates, developed by WHO/ UNICEF/United Nations Population Fund (UNFPA) and the World Bank 
were also reviewed to measure the progress towards MDGs in Pakistan.

\section{Results}

Table 1 illustrates maternal and reproductive health (RH) indicators from 1990 to 2006 and shows improvement in antenatal care, increasing from $15 \%$ to $61 \%$, and tetanus toxoid coverage showing that six out of 10 women have been vaccinated (not shown in table). Deliveries attended by skilled birth attendants remained low (39\%), 83\% of which took place in health facilities (not shown in table). The contraceptive prevalence rate stagnated at $30 \%$, although knowledge about FP reached 90\% (not shown in table). The U5MR and IMR were estimated at 94/1000 live births and 78/1000 live births, respectively, while NNMR was 54/1000 live births. Only $47 \%$ of children were fully immunized, the percentage having dropped steadily since 1990 according to PDHS 2006-2007, although the reported coverage of three doses of vaccine against diphtheria, pertussis and tetanus in 2009 was $83 \%$ [20]. Exclusive breastfeeding for 6 months was only practiced in $37 \%$ of infants (not shown in table).

Table 2 shows that the pace of reduction in IMR, NNMR and U5MR over the past 16 years was relatively slow, with a yearly improvement of 1.5 , 0.2 and 2.1 percentage points, respectively. The lowest gain was associated with neonatal mortality, already accounting for a major portion of infant and under-five deaths (69\% and 57\%, respectively). By then the MMR was on track relative to the annual incremental gains accrued since 1990.

Figure 1 reveals that the reduction of U5MR during 1990-2006 was predominantly achieved through a decrease in postneonatal (1-11 months) and child deaths ( $1-4$ years), while the $\operatorname{NNMR}(<1$ month) showed insignificant changes, accounting for more than $57 \%$ of U5MR on average.

Figure 2 shows the disparity in $\mathrm{MNCH}$ services, including RH/FP between the functionally comparable units operated by Ministry of Health/ Department of Health and Ministry of Population Welfare facilities. The first-level care facilities (FLCFs) traditionally affiliated and managed by the health sector, offered $\mathrm{MNCH}$ services that were not comprehensive in terms of RH and FP, while the FLCFs managed by the Ministry of Population Welfare were less comprehensive in providing EmONC and essential newborn care services, reflecting the missed opportunities in the provision of these essential services.

Table 3 displays the challenges faced and the solutions required for achieving MDGs 4 and 5 by 2015. Cost-effective interventions are identified, many of these being under implementation. The table also outlines the operational prerequisites necessary for universal coverage, access and utilization. These include the training and deployment of 30000 CMWs within five years; equipping and manning 1200 referral facilities for the provision of round-the-clock comprehensive EmONC services; and

\begin{tabular}{|c|c|c|c|c|c|c|}
\hline Indicator & $\begin{array}{c}1990 \\
\text { (MDGR) }\end{array}$ & $2000^{\mathrm{a}}$ & $2003^{b}$ & $\begin{array}{l}2005 \\
(\text { PSLM) }\end{array}$ & $\begin{array}{c}2006 \\
\text { (PDHS) }\end{array}$ & $\begin{array}{l}2015 \text { MDG } \\
\text { targets }\end{array}$ \\
\hline Infant mortality rate (per 1000 live births) & 102 & 77 & 103 & 70 & 78 & 40 \\
\hline Neonatal mortality rate (per 1000 live births) & 56 & 52 & - & - & 54 & No target \\
\hline Under-five mortality rate (per 1000 live births) & 140 & 105 & 75 & - & 94 & 52 \\
\hline Immunization 12-23 months (\%) & 75 & 53 & 55 & 49 & 47 & $>90$ \\
\hline $\begin{array}{l}\text { Proportion of children under one year immunized } \\
\text { against measles (\%) }\end{array}$ & NA & 55 & 57 & 52 & 82 & $>90$ \\
\hline $\begin{array}{l}\text { Prevalence of underweight/malnourished under- } \\
\text { five-year-olds (\%) }\end{array}$ & 49 & $37^{c}$ & 40 & $37^{c}$ & $37^{c}$ & $<10$ \\
\hline Maternal mortality ratio (per 100000 live births) & 550 & 350 & 350 & 350 & 276 & 140 \\
\hline Birth assisted by skilled birth attendant (\%) & 18 & 40 & 40 & 39 & 39 & $>90$ \\
\hline $\begin{array}{l}\text { Proportion of women } 15-49 \text { years who had given } \\
\text { birth during past } 3 \text { years, who had attended } \\
\text { at least one antenatal care consultation (\%) }\end{array}$ & 15 & 35 & 35 & 52 & 61 & 100 \\
\hline Total fertility rate (births/woman) & 5.4 & 4.5 & 3.9 & 3.9 & 4.1 & 2.1 \\
\hline Contraceptive prevalence rate (\%) & 12 & 33 & 33 & 33 & 30 & 55 \\
\hline
\end{tabular}

a Planning Commission.

${ }^{b}$ Pakistan MDG report (baseline).

cNational nutrition survey 2001-2002.

MDGR = Pakistan Millennium Development Goals report; PDHS = Pakistan demographic and health survey 2006-2007; PSLM = Pakistan social and living standards measurement survey 2005-2006; NA= not available. 


\begin{tabular}{|c|c|c|c|c|c|c|}
\hline Indicator & $\begin{array}{c}1990 \\
\text { baseline } \\
\text { (MDGR) }\end{array}$ & $\begin{array}{c}2006 \\
\text { performance } \\
\text { (PDHS) }\end{array}$ & $\begin{array}{c}\text { Points } \\
\text { gained per } \\
\text { year }^{\mathrm{a}}\end{array}$ & $\begin{array}{c}2015 \text { expected } \\
\text { mortality rates } \\
\text { with the current } \\
\text { pace }^{\mathrm{a}}\end{array}$ & $\begin{array}{c}\text { MDG } \\
\text { target } 2015 \\
\text { (MDGR) }\end{array}$ & $\begin{array}{c}\text { Yearly reduction } \\
\text { pace to achieve } \\
\text { MDG targets by } \\
2015^{\mathrm{a}}\end{array}$ \\
\hline Maternal mortality ratio ${ }^{b}$ & 550 & 276 & 3.1 & 139 & 140 & 3.1 \\
\hline Infant mortality rate ${ }^{c}$ & 102 & 78 & 1.5 & 66 & 40 & 4.7 \\
\hline Neonatal mortality rate ${ }^{c}$ & 56 & 54 & 0.2 & 53 & 18 & 7.8 \\
\hline Under-five mortality rate ${ }^{c}$ & 140 & 94 & 2.1 & 71 & 52 & 3.8 \\
\hline
\end{tabular}

${ }^{a}$ Calculated from baseline (1990) and 2006 mortality rates; ${ }^{b}$ per 100000 live births; ${ }^{c}$ per 1000 live births. MDGR = Pakistan MDG report; PDHS = Pakistan demographic and health survey 2006-2007.

the scaling-up of integrated management of newborn and child illness/ essential newborn care/prenatal care coverage, by ensuring their effective delivery in $90 \%$ of FLCFs from the current level of $54 \%$.

\section{Discussion}

During the past two decades, Pakistan has accomplished reasonable gains in reducing maternal, infant and underfive mortalities: from 1990 to 2006 the MMR, U5MR and IMR have dropped by $50 \%, 24 \%$ and $33 \%$, respectively. Despite this tangible progress, Pakistan may not advance sufficiently to reach the set MDG targets by 2015, and hence is lagging behind other countries of comparable socioeconomic development. The relatively lower reduction in the IMR and USMR can primarily be attributed to the nearly stagnant NNMR, which progressed only $4 \%$ over the same period.

Pakistan's national MDG report of 2004 charted a road map for enhancing maternal and child survival by placing greater emphasis on reducing maternal and neonatal mortality through:

- training and deployment of community-based skilled birth attendants;

- ensuring access to quality basic and comprehensive EmONC referral services in the rural and urban marginalized areas;

- introducing a unified policy on maternal and child health through holistic interventions;

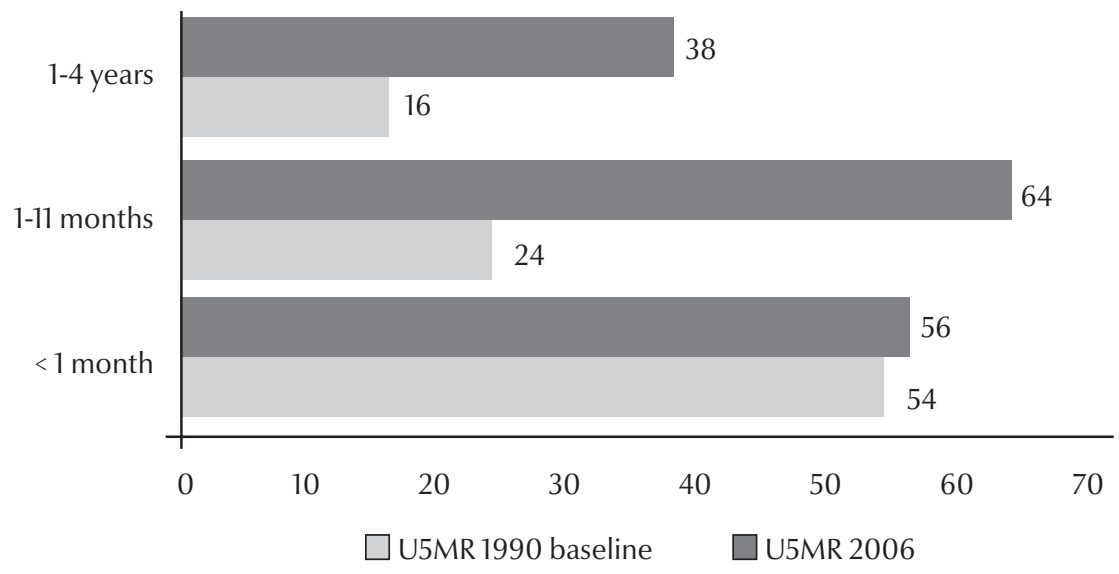

Figure 1 Neonatal, infant and child mortalities: comparison between 1990 baseline and 2006 under-five mortality rate (U5MR) (per 1000 live births) by age group

- integrating and promoting maternal and child nutrition;

- encompassing social safety nets and health insurance schemes;

- fostering behaviour change targeting both men and women.

Pakistan can timely achieve MDG5 if the reported pace of reduction in MMR is sustained and accelerated; however, with a contraceptive prevalence rate stagnating at 30\%, a low rate of deliveries assisted by a skilled birth attendant (39\%) and the lack of accessible and quality EmONC services, this task is most challenging. The prevention of unplanned pregnancies alone could avert around one-quarter of maternal deaths, including those resulting from unsafe abortions, by addressing the large unmet need for child spacing [11]. Although a range of socioeconomic factors may influence maternal survival, the major focus needs to be directed to health system strengthening, enabling universal delivery of essential $\mathrm{MNCH}$ services that are effective and affordable to the underprivileged strata of society. The U5MR and IMR will only make a real breakthrough when the stagnating NNMR is addressed effectively.

The observed fragmentation in the delivery of MNCH services, including RH and FP, by the Ministry of Health and Ministry of Population Welfare constitutes a major challenge, as close to 10000 FLCFs run by the health sector need to strengthen their RH and FP service delivery capacities to avert the 


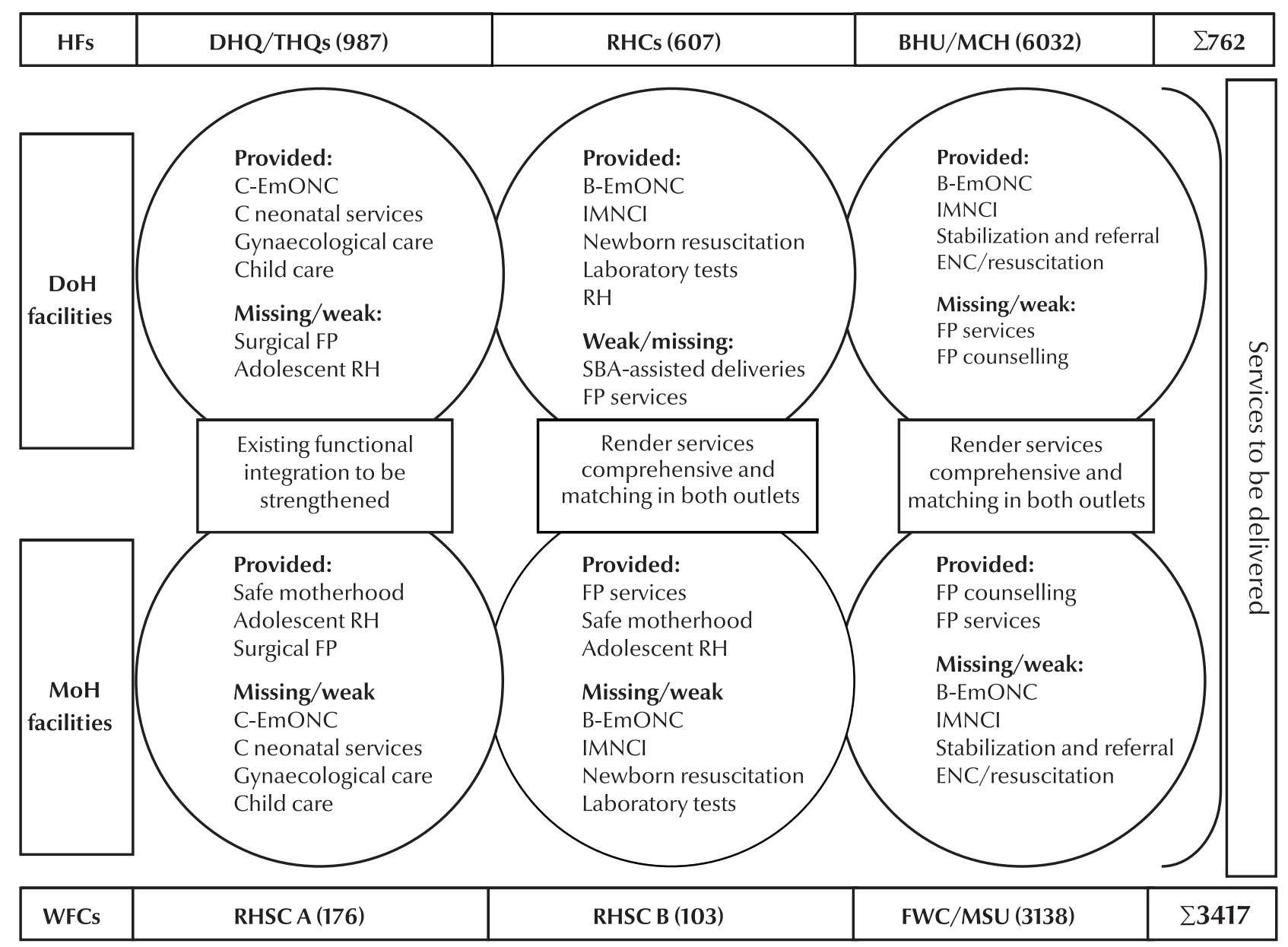

Figure 2 Discrepancies in maternal neonatal and child health $(\mathrm{MNCH})$ service delivery in comparable service delivery outlets administered by the health and population sectors and the need for comprehensive functional integration.

$\mathrm{B}-\mathrm{EmONC}=$ basic emergency obstetric and neonatal care; $\mathrm{BHU}=$ basic health unit; $\mathrm{DHQ}=$ district headquarters; $\mathrm{DoH}=$ Department of Health; C-EmONC = comprehensive emergency obstetric and neonatal care; ENC = essential newborn care; $\mathrm{FP}=$ family planning; FWC/MSU = family welfare centre/mobile service unit; $\mathrm{HFs}=$ health facilities; $\mathrm{IMNCI}=$ integrated management of newborn and child illness; $\mathrm{MCH}=$ maternal and child health centre; $\mathrm{MoH}=$ Ministry of $\mathrm{Health}$; $\mathrm{RH}=$ reproductive health; $\mathrm{RHC}=$ rural health centre; $\mathrm{RHSC}=$ reproductive health services centre; $\mathrm{SBA}=$ skilled birth attendant; THQ = tehsil headquarters; WFCs =welfare centres.

huge quantum of missed opportunities resulting from the unsatisfactory provision of these essential services. On the other hand, the 3000 facilities operated by the Ministry of Population Welfare were primarily providing RH and FP services but were less equipped to provide comprehensive preventive, promotive and curative $\mathrm{MNCH}$ services at their outlets. These operational gaps could be addressed through a coordinated joint effort, where the planning, financing, implementation, supervision and monitoring of $\mathrm{MNCH}$ services are regarded as a shared responsibility, and where the two ministries and their respective provincial and district counterparts work closely together to upgrade their facilities. This would involve the implementation of a package of essential MNCH services at each service delivery level, based on the concepts of functional integration and a minimum essential service package, enabling mothers and children to avail the envisaged $\mathrm{MNCH} / \mathrm{RH} / \mathrm{FP}$ services when seeking care from any of these facilities [20]. The FLCFs run by the health sector should also provide comprehensive EmONC referral support and this would have a significant positive impact on maternal and child survival.

A major driving force of the high maternal and neonatal mortality in $\mathrm{Pa}$ kistan is the large number of mothers assisted by unskilled birth attendants during delivery; out of the $66 \%$ home deliveries, only $7.6 \%$ were assisted by a skilled birth attendant. Current countrywide estimates of available skilled birth attendants, including obstetricians, nurses/midwives, lady health visitors and CMWs, may not exceed 12 000, while the required midwifery workforce is estimated at 30000 for the next 5 


\begin{tabular}{l}
\hline Table 3 Challenges, solutions and operational implications to attain Millennium Development Goals (MDGs) 4 and 5 by 2015 \\
$\begin{array}{lcc}\text { Challenges } & \text { Solutions }\end{array}$
\end{tabular}

\section{MDG 4}

Vaccination coverage of $>90 \%$ for $12-23$ month children

Achieving $>90 \%$ coverage of measles vaccination

Scaling-up and implementing $\mathrm{IMNCI}$, essential newborn care and postnatal care coverage to $>90 \%$ of FLCFs

Accelerating the pace of reduction in neonatal mortality

\section{MDG 5}

Increasing number of deliveries assisted by SBAs and encouraging facility-based deliveries

Tangible improvement in FP services

Addressing all forms of maternal and child malnutrition
Focusing on unreached and underserved populations in urban slums and rural areas Involving the private sector and NGOs Introducing $\mathrm{IMNCl}$ and child survival projects in preservice training

Ensuring ANC, PNC, skilled attendance at birth, and timely referral

More coordination between EPI, LHWs, Training LHVs/LHWs on ENC and PNC nutrition and $\mathrm{MNCH}$

Training all SBAs, paediatricians and WMOs on neonatal resuscitation

Producing and deploying critical mass of CMWs/SBAs

Training and deployment of more than $30000 \mathrm{CMWs}$ in the next 5 years in rural areas and slums

Raising public awareness regarding SBA Making SBAs available for assisted normal deliveries in 987 and facility-based deliveries THQ/DHQ, 607 RHCs, 279 RHCA\&B and 3138 FWCs

Availability of round-the-clock C-EmONC services in 987 THQ/DHQ and 279 RHCA\&B

Functional integration of FP services between $\mathrm{MoPW} / \mathrm{MoH}$ outlets

Addressing unmet needs

Raising public awareness

Providing FP services in more than $10000 \mathrm{MoH}$ health facilities and 3417 MoPW WFCs

Training and involvement of all CMWs/LHVs and LHWs in FP services

Training staff and involving all private sector facilities

Providing FP services in all health outlets

Strengthening health system especially human resources (WMOs)

Providing supplies, equipment and timely referral

Allocating more resources

Bridging deficiencies of both macro- Iron/folate supplementation for all pregnant women, and micronutrients (especially iron and vitamin A supplementation for all under-five children by iodine) more than 100000 LHWs

Managing severe malnutrition and establishing therapeutic feeding centres in more than $987 \mathrm{DHQ} / \mathrm{THQ}$ hospitals

Improving care-seeking Focusing on awareness, health behaviours and demand creation education and behavioural changes

Utilizing innovative ideas, e.g. vouchers schemes, cash transfer and in-kind incentives (food rations, oil)

Increasing emphasis on the poor, slums Developing prepayment mechanisms through revamped and vulnerable groups public sector or through social, private and communitybased health insurance

$A N C=$ antenatal care; $C$-EmONC = comprehensive emergency obstetrics and neonatal care; $C M W s=$ community midwives; THQ $D H Q=$ tehsil headquarters $/$ district headquarters; $E N C=$ essential newborn care; $E P I=$ Expanded Programme on Immunization; FP = family planning; FLCFs = first-level care facilities; FWCS = family welfare centres; IMNCl, integrated management of newborn and child illness; LHVS = lady health visitors; LHWs = lady health workers; MNCH= maternal neonatal and child health; $\mathrm{MoH}=$ Ministry of Health; $\mathrm{MoPW}=$ Ministry of Population Welfare; $\mathrm{MNCH}=$ maternal neonatal and child health; $\mathrm{NGOs=nongovernmental}$ organizations; $O R S=$ oral rehydration salts; $P N C=$ prenatal care; $R H C s=$ rural health centres; $R H C A \& B=$ reproductive health centre type $A \& B ; S B A s=$ skilled birth attendants; $W F C s=$ welfare centres; $W M O s=$ women medical officers. 
years. This estimate is determined by envisaging one CMW for every 5000 catchment area population, with the CMW performing on average at least 150 deliveries per year, in addition to over 1000 antenatal and postnatal visits. The proposed coverage is lower than that indicated by the Safe Motherhood Initiative, where one skilled birth attendant is required for every 2000 population, but still challenging both in operational and financing terms, underscoring the need for international partnerships to successfully embark on this major undertaking [21].

Pakistan may repeat its globally acknowledged success in the training and deployment of over 100000 lady health workers by assuming a similar political commitment and declaring a crash programme for the training and deployment of CMWs. To accomplish this mission within the set time frame, CMW training needs to be conducted in all tertiary, district headquarter and tehsil headquarter hospitals, securing the necessary equipment and qualified human resources. The initiative will concurrently ensure the delivery of comprehensive EmONC referral services and allow assisted home deliveries through community-based outreach services. The placement of third-year postgraduate students registered at the College of Physicians and Surgeons of Pakistan in district and tehsil headquarter hospitals for 6-12 months as part of their residence training and employing 2-3 nurses/midwives in each participating hospital unit would largely mitigate the human resource gap and render the process feasible.

This gigantic task should entail mobilizing support from the 64 medical universities/colleges of Pakistan, College of Physicians and Surgeons of Pakistan, Midwifery Association of Pakistan, Pakistan Nursing Council, Society of Obstetrics and Gynaecology of Pakistan and the 110 currently operational nursing and midwifery schools in the country, generating a nationwide movement to attain this critical social goal. A series of national meetings with active interprovincial and district participation should be organized to build a nationwide consensus for this flagship health reform intervention. Once trained, the CMWs could maintain a contractual employment relationship with the national health system, similar to the approach pursued for lady health workers. The latter will substantiate their close affiliation with the health system in terms of supervision and monitoring, recording and reporting, continuing education and the provision of basic supplies and equipment.

In view of the obvious preference of most rural mothers to give birth at home, it would be unrealistic to envision a CMW clinic for conducting deliveries, as opposed to the culturally preferred mode of attending births at home. Organizing transport facilities to promptly access comprehensive EmONC services is another major undertaking, requiring active coordination of households and local community organizations. As an intermediate strategy and based on recent evidence showing that traditional birth attendants can impact on reducing perinatal and neonatal mortality and stillbirths [22], their skill training on clean deliveries, combined with improved linkages with the health system, could be considered for rural areas where access to CMW services is remote. However, the ultimate objective should be the deployment of skilled birth attendants in all rural areas to ensure access to quality services.

From 1990 to 2006, the decline in U5MR was mostly from reductions in postneonatal (1-11 months) and child (1-4 years) mortalities, while the NNMR has remained almost stagnant, indicating the need for enhancing efforts to attain MDG 4 targets by 2015 with an unyielding focus on reducing the NNMR. More than $62 \%$ of deaths in under-five children can be averted by ensuring universal coverage with the $16 \mathrm{WHO}$-supported interventions identified by the Bellagio Study Group on Child Survival, which were selected by the national $\mathrm{MNCH}$ programme as evidence-based child health interventions [23]. Three-quarters of perinatal deaths and at least $30 \%-40 \%$ of infant deaths can be averted through improved maternal health, adequate nutrition during pregnancy, effective antenatal services and deliveries assisted by a skilled birth attendant with neonatal resuscitation and postnatal visits [24]. In addition, household and community newborn care, correct breastfeeding practices, keeping the baby warm, recognizing when to seek care and timely referral to RH centres and hospital emergency neonatal care units can contribute significantly to newborn survival [23,25].

Other critical interventions include maintaining full immunization coverage of children aged 12-23 months at more than $90 \%$ and scaling-up and implementing integrated management of newborn and child illness, essential newborn care and prenatal care in more than $90 \%$ of FLCFs.

The private sector role in $\mathrm{MNCH}$ and RH service delivery is crucial to improving access to these vital services, hence the need to engage a large number of practicing family physicians. A platform of advocacy and public education on $\mathrm{MNCH}, \mathrm{RH}$ and FP relevant to maternal and child survival has to be generated. Demand creation, utilization of available services, support through voucher schemes, conditional cash transfers, the possible link with the Benazir Income Support Programme, and development of prepayment mechanisms through revamped public sector or through social, private and community-based health insurance schemes for the poor, are critical elements that would improve access to these vital services.

The Federal Government approved the national $\mathrm{MNCH}$ programme in 2007 at a cost of PKR 20 billion (about US\$ 333.3 million) to adopt 
and implement proven cost-effective interventions and attain MDG 4 and 5 targets. The programme has developed strong partnerships reflected in the technical and financial support provided by UN agencies, especially WHO, UNICEF, UNFPA and the "Delivering as One" joint programme; health development partners including AusAID, Department for International Development (DFID), Japan International Cooperation Agency (JICA), United States Agency for International
Development (USAID) and World Bank; GAVI Health System Strengthening Support (GAVI HSS); and bilateral initiatives such as the Norway-Pakistan Partnership Initiative. The government has to reinforce its commitment to $\mathrm{MNCH}$ through an incremental budgetary outlay and international resource mobilization, while ensuring the effective and nationwide implementation of the programme.

Over the past two decades, Pakistan has accomplished reasonable gains in reducing maternal, infant and underfive mortality rates, as from 1990 to 2006. Despite this tangible progress, achieving MDGs 4 and 5 may be delayed unless the prospected range of maternal and child survival interventions are scaled-up, with a strong focus on the production and deployment of a critical mass of CMWs linked to the health system, and by a major improvement of RH and FP services, supported by a strong partnership and active community participation.

\section{References}

1. Ahmad OB, Lopez AD, Inoue M. The decline in child mortality: a reappraisal. Bulletin of the World Health Organization, 2000, 78:1175-1191.

2. The world health report 2002: reducing risks, promoting healthy life. Geneva, World Health Organization, 2002.

3. Child mortality statistics. New York, United Nations Children's Fund (http://www.childinfo. org/cmr/revis/db2.htm, accessed 21 January 2010).

4. Hill K et al., eds. Trends in child mortality in the developing world, 1960-1996. New York, United Nations Children's Fund, 1998.

5. Ezzati M et al., eds. Comparative quantification of death risks: global and regional burden of disease attributable to selected major factors. Geneva, World Health Organization, 2006.

6. Costello AM. Prenatal health in developing countries. Transactions of the Royal Society of Tropical Medicine and Hygiene, 1993, 87:1-2.

7. Maternal mortality in 2005: estimates developed by WHO, UNICEF, UNFPA and the World Bank. Geneva, World Health Organization, 2007.

8. Hogan MC et al. Maternal mortality for 181 countries, 19802008: a systematic analysis of progress towards millennium development Goal 5. Lancet, 2010, 375(9726):1609-1623.

9. Neonatal mortality in EMR, determinants and strategies for achieving MDG 4. Cairo, World Health Organization, Regional Office for the Eastern Mediterranean, 2007.

10. Lawn JE et al. 4 million neonatal deaths: when, where and why? Lancet, 2005, 365(9462):891-900.

11. Pakistan demographic and health survey (PDHS) 2006-2007. Islamabad, National Institute of Population Studies, 2007.

12. Pakistan country profile: analysis of demographic health surveys. Geneva, World Health Organization, Department of Making Pregnancy Safer, 2009.
13. Siddiqi $\mathrm{S}$ et al. A critique of maternal and child health policy in Pakistan. Oxford, Oxford University Press, 2004.

14. Pakistan integrated household survey 2001-2. Islamabad, Federal Bureau of Statistics, 2002.

15. Pakistan Medical Research Council, health survey of Pakistan. Islamabad, Medical Research Council, Ministry of Health, 1998.

16. Pakistan demographic and health survey 2006-2007. Islamabad, National Institute of Population Studies, 2007.

17. Pakistan integrated household survey 2001-2002. Islamabad, Federal Bureau of Statistics, 2002.

18. Nishtar S, Amjad S. Synergizing health and population in Pakistan. Journal of Pakistan Medical Association, 2009 (Suppl.3):S3S20.

19. Bile K. The imperative of functional integration for achievement of MDGs. Journal of Pakistan Medical Association, 2009, 59(9 Suppl. 3):S34-38:

20. National EPI report. Islamabad, Ministry of Health, 2009.

21. The world health report 2005: make every mother and child count. Geneva, World Health Organization, 2005.

22. Sibley LM et al. Traditional birth attendant training for improving health behaviours and pregnancy outcomes. Cochrane Database of Systematic Review, 2007, 3 (No.CD005460).

23. Jones $\mathrm{G}$ et al. How many child deaths can we prevent this year? Lancet, 2003, 362:65-71.

24. Bhutta ZA. Maternal and child malnutrition in Pakistan: challenges and opportunities. Oxford, Oxford University Press, 2004.

25. Bhutta ZA. Shaping policy for maternal and newborn health: a compendium of studies. Baltimore, MD, Bill and Melinda Gates Foundation, 2003:5-12. 